\title{
Design of 32-bit Floating Point Unit for Advanced Processors
}

\author{
Amana Yadav ${ }^{*}$ Ila Chaudhary ${ }^{* *}$ \\ Electronics and Communication Department, Faculty of Engineering and Technology, \\ Manav Rachna International University, Faridabad
}

\begin{abstract}
Floating Point Unit is one of the integral unit in the Advanced Processors. The arithmetic operations on floating point unit are quite complicated. They are represented in IEEE 754 format in either 32-bit format (single precision) or 64-bit format (double precision). They are extensively used in high end processors for various applications such as mathematical analysis and formulation, signal processing etc. This paper describes the detailed process for the computation of addition, subtraction and multiplication operations on floating point numbers. It has been designed using VHDL. The design has been simulated and synthesized to identify the area occupied and its performance in terms of delay.
\end{abstract}

Keywords: Arithmetic operations, Floating point, IEEE standard 754, VHDL

\section{INTRODUCTION}

The real numbers may be described informally as numbers that can be given by an infinite decimal representation, such as $2.48717733398724433 \ldots$. The real numbers include both rational numbers, such as 56 and $-23 / 129$, and irrational numbers, such as $\pi$ and the square root of 2 , and can be represented as points along an infinitely long number line. They can have fixed point as well as floating point representation. Computation of floating point numbers needs advanced processing techniques. Advanced processors have dedicated floating point processor unit which is capable of performing arithmetic operations on real numbers with single precision (32-bits format)[1] or double precision(64-bits format).

Floating point notation is represented in the form as follows[2]:

$\mathrm{n}=\mathrm{b}^{\mathrm{e}} * \mathrm{~m}$

where,

$\begin{array}{lll}\mathrm{n} & = & \text { the number to be represented } \\ \mathrm{b} & = & \text { base } \\ \mathrm{m} & = & \text { mantissa }\end{array}$

Value of $b$ is

' 2 ' for binary numbers

' 8 ' for octal numbers

' 10 ' for decimal numbers

' 16 ' for hexadecimal numbers

In floating point arithmetic[3] user can round off the results of the computations as per his requirement but IEEE standard 754 defines the rules that lead to the same result of computation by rounding off. It prevents the existence of different results in different computations for the same input.
Single precision 32 - bit floating point format 32- bit floating point representation as per IEEE follows the standard shown in fig. 1

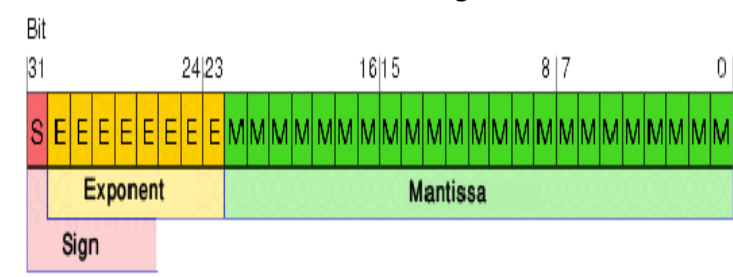

Fig. 1: IEEE 754 standard for single precision representation

The most significant bit starts from the left.

The number represented in the single precision format is

Value $=(-1) \mathrm{s} 2 \mathrm{e} \times 1 . \mathrm{f}$ (normalized) when $\mathrm{E}>0$ else $=(-1) \mathrm{s} 2-126 \times 0 . \mathrm{f}($ denormalized $)$ where,

f $=(\mathrm{b} 23-1+\mathrm{b} 22-2+$ bi n $+\ldots+$ b0 -

23 ) where bi $n=1$ or 0

$\mathrm{s} \quad=\quad \operatorname{sign}(0$ is positive; 1 is negative $)$

$\mathrm{E} \quad=\quad$ biased exponent; $\operatorname{Emax}=255$,

Emin=0. $E=255$ and $E=0$ are used to represent special values.

$\mathrm{e} \quad=\quad$ unbiased exponent; $\mathrm{e}=\mathrm{E}-$ 127(bias)

A bias of 127 is added to the actual exponent to make negative exponents possible without using a sign bit. So for example if the value 105 is stored in the exponent placeholder, the exponent is actually $-22(105-127)$. Also, the leading fraction bit before the decimal point is actually implicit and can be 1 or 0 depending on the exponent and therefore saving one bit. After the arithmetic computation of a number it is required to 
normalize the result which means that MSB 1 is in the most left bit of the fractional part. It is done for representation of the number in only one way else same number can be written in hundreds of ways if kept in denormalized form.

\section{Exceptions in floating point Unit}

Various exceptions are defined by IEEE standard 754 which helps in implementing the arithmetic at the hardware level[5]. These exceptions are listed below:

Invalid operations: Some arithmetic operations are invalid, such as a division by zero or square root of a negative number. The result of an invalid operation shall be a NaN. There are two types of $\mathrm{NaN}$, quiet $\mathrm{NaN}(\mathrm{QNaN})$ and signaling $\mathrm{NaN}(\mathrm{SNaN})$. They have the following format, where $\mathrm{s}$ is the sign bit:

$\mathrm{QNaN}=\mathrm{s} 1111111110000000000000000000000$

$\mathrm{SNaN}=\mathrm{s} 1111111100000000000000000000001$

\section{Division by Zero}

The division of a number (except zero) by zero gives infinity as a result. However, other arithmetic operations such as addition or multiplication may also give infinity as a result. The addition or multiplication of two numbers may also give infinity as a result. Therefore, to differentiate between the two cases, a divide-by-zero exception was implemented. Other exceptions that are defined by the IEEE standard are listed as Inexact, underflow, overflow, infinity and zero. Different rounding modes used are Round to nearest even, Round-tozero, Round-up and Round-Down.

\section{ARITHMETIC OPERATIONS}

Addition / Subtractions[4]: A similar procedure is to be followed for the implementation of addition and subtraction. Hence, a single unit is used for these operations.

Table 1 shows an example of two operands considered for the computation.

Table1. IEEE standard 754 representation of the operands considered for the inputs

\begin{tabular}{|l|c|c|}
\hline & Operand A & Operand B \\
\hline $\begin{array}{l}\text { Decimal } \\
\text { Values }\end{array}$ & 2.5 & 4.75 \\
\hline Sign bit & 0 & 0 \\
\hline Exponent & 10000000 & 10000001 \\
\hline Fraction & $\mathbf{1 . 0 1 0 \ldots \ldots . . 0 _ { 2 }}$ & $\mathbf{1 . 0 0 1 1 0 \ldots . . 0 _ { 2 }}$ \\
\hline
\end{tabular}

Addition: Following are the steps followed for the addition of two floating point operands:

1. Finding the difference of exponents

Diff $=10000001-10000000=00000001$

Exponent A is smaller than exponent $\mathrm{B}$ by 1-bit
2. Shifting the fraction of the operand A (smaller one) to the right

$$
\text { fraction } \mathrm{A}=0.1010 \ldots 0_{2}
$$

3 . Incrementing the exponent A by ' 1 ' to equalize it to the larger one.

4. Adding the two fraction parts

Fract $_{\text {out }}=0.1010 \ldots .0_{2}+1.00110 \ldots 0_{2}=$

$1.11010 \ldots .0_{2}$

5. Normalizing the result if necessary

6. Writing the result

Output $=01000000111010 \ldots \ldots 0_{2}$

Subtraction:- For subtraction similar procedure is followed accept that the fraction part is subtracted. Fig. 2. Shows the flow chart for addition and subtraction of floating point numbers using floating point arithmetic.

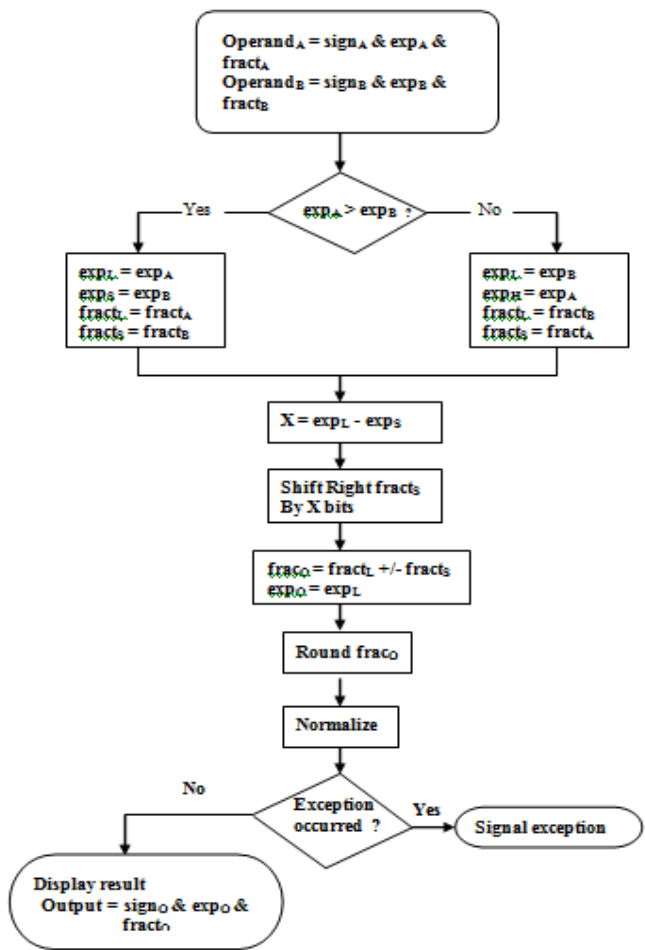

Fig. 2: Flow chart for addition / subtraction

\section{Multiplication:}

A separate block is to be provided for the multiplication of the floating point numbers. Steps followed for the process of multiplication are as follows:

1. Adding two exponents and subtracting the bias 127

Exponent out $=10000000+10000001-10000010$

2. Multiplying the fraction out $=1.0011 * 1.01$ by standard multiplication algorithm.

Result $=1.0111111$

3. Normalize the result if necessary and give the output

Output $=0100000100111110 \ldots \ldots 0_{2}$ 
Fig. 3 shows the flow chart for the process of multiplication.

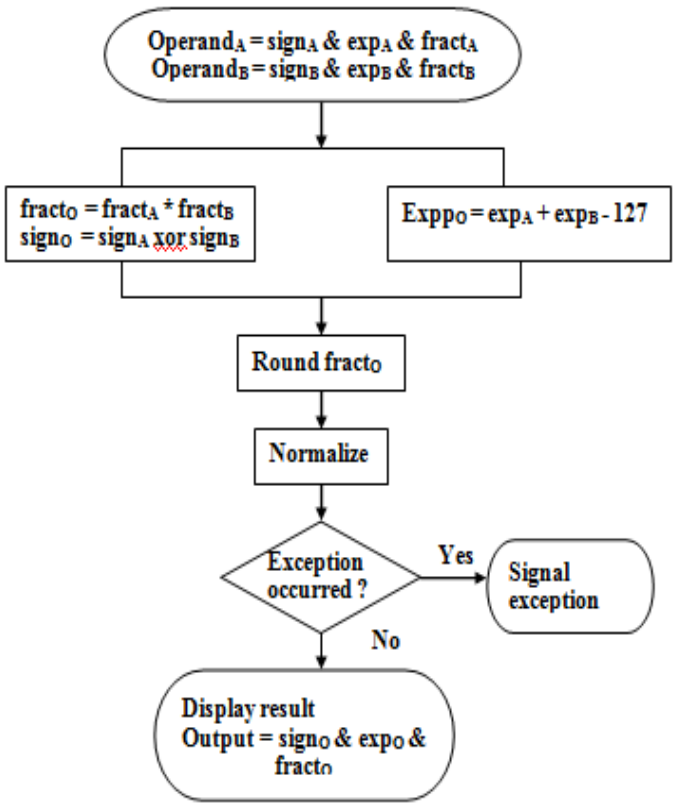

Fig. 3.: Flow chart for Multiplication

Fig. 4 shows the architecture of Floating Point Unit. Inputs to FPU

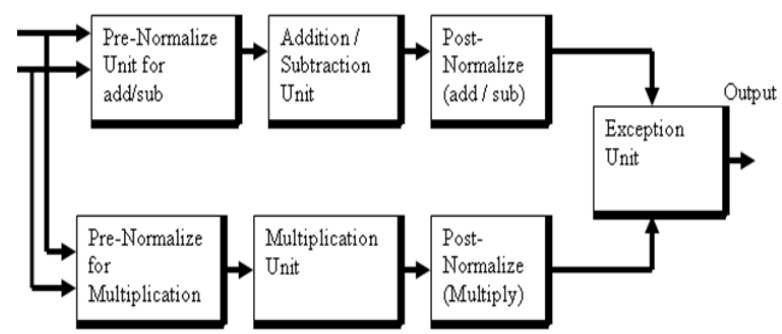

Fig. 4: Architecture of floating point Unit

\section{IMPLEMENTATION}

Fig. 5 shows main entity of Floating Point Unit.

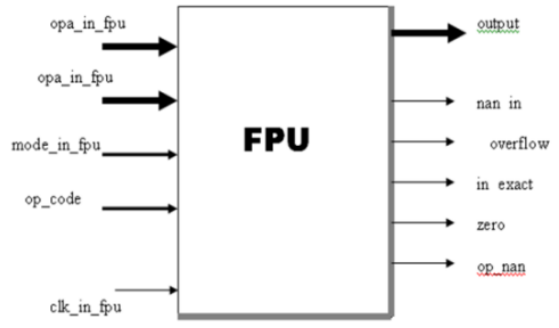

Fig. 5: Top level entity of FPU

Two input operands are forwarded to the pre-normalization unit. Also, other inputs like opcode telling the operation to be performed and rounding mode inputs are also send to the internal unit.
Pre-normalization unit for addition / subtraction

Function:- Input operands to the FPU are send to pre-normalization unit for add-sub. It performs the following functions.

1. It separates the exponent and the fraction part with 8-bits of exponent and 23 bits of fraction.

2. Fraction is expanded as:- Carry(1) \& Hidden(1) \& Fraction(23) \& Guard(1) \& Round(1) \& Sticky(1). Hidden bit is ' 1 ' and three zeros added at the end that help to prevent the loss of data during rounding and shifting.

3. Checks which exponent is larger and finds there difference.

4. Sends larger exponent as the output.

5. Shifts the fraction part of the exponent to the right with the smaller exponent.

6. Sends the fractions to add / sub unit.

Fig. 6 shows the pre-normalize unit. Also, inputs/outputs are described in Table 2.

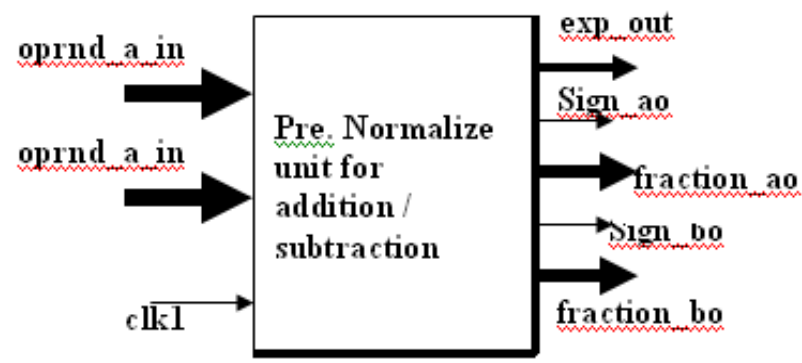

Fig.6: Pre-normalization unit

Table 2: Inputs / Outputs of Pre-Normalize Unit

\begin{tabular}{|l|c|l|}
\hline $\begin{array}{l}\text { Input / } \\
\text { Output }\end{array}$ & $\begin{array}{l}\text { No. of } \\
\text { bits }\end{array}$ & Description \\
\hline clk1 & 32 & $\begin{array}{l}\text { Acts as clock for this } \\
\text { unit }\end{array}$ \\
\hline oprnd_a_in & $\begin{array}{l}\text { FPU by user for } \\
\text { computation }\end{array}$ \\
\hline oprnd_b_in & 32 & $\begin{array}{l}\text { Input operand B to } \\
\text { FPU by user for } \\
\text { computation }\end{array}$ \\
\hline Fraction_ao & 28 & $\begin{array}{l}\text { Output fraction A to } \\
\text { add / sub unit }\end{array}$ \\
\hline Fraction_bo & 28 & $\begin{array}{l}\text { Output fraction B to } \\
\text { add / sub unit }\end{array}$ \\
\hline exp_out & 8 & $\begin{array}{l}\text { Larger exponent as } \\
\text { output to post- } \\
\text { normalize unit }\end{array}$ \\
\hline Sign_ao & 1 & Sign bit of operand A \\
\hline Sign_ao & 1 & Sign bit of operand B \\
\hline
\end{tabular}

\section{Addition / Subtraction Unit:}

Inputs / Outputs:- This unit takes the output of the pre-normalize unit as the input, performs addition or subtraction depending on the opcode. Table 3 describes the inputs / outputs of the unit and Fig. 7 shows them. 


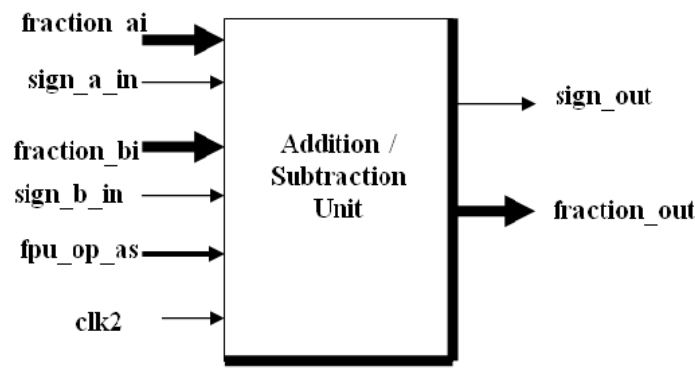

Fig. 7: Addition / Subtraction Unit

Table 3 Inputs / outputs of Addition / Subtraction

\begin{tabular}{|l|c|l|}
\hline $\begin{array}{l}\text { Input / } \\
\text { Output }\end{array}$ & $\begin{array}{l}\text { No. of } \\
\text { bits }\end{array}$ & Description \\
\hline clk2 & $\begin{array}{l}\text { Act as clock for this } \\
\text { unit }\end{array}$ \\
\hline fpu_op_as & 2 & $\begin{array}{l}\text { Opcode telling whether } \\
\text { addition or subtraction } \\
\text { to be performed }\end{array}$ \\
\hline fraction_ai & 28 & $\begin{array}{l}\text { Output fraction A from } \\
\text { pre-normalize unit }\end{array}$ \\
\hline fraction_bi & 28 & $\begin{array}{l}\text { Output fraction B from } \\
\text { pre-normalize unit }\end{array}$ \\
\hline sign_a_in & 1 & $\begin{array}{l}\text { MSB of the operand A } \\
\text { i.e. sign bit }\end{array}$ \\
\hline sign_b_in & 1 & $\begin{array}{l}\text { MSB of the operand B } \\
\text { i.e. sign bit }\end{array}$ \\
\hline sign_out & 1 & $\begin{array}{l}\text { Output sign of the } \\
\text { result after } \\
\text { computation }\end{array}$ \\
\hline fraction_out & 28 & Fraction result \\
\hline \multicolumn{2}{|l}{} \\
\end{tabular}

Post Normalization Unit:

Function:- The result obtained from the addition / subtraction unit is fed to the post-normalize unit shown in Fig. 8. Table 4 describes the inputs/ outputs of post-normalization unit.

It performs the normalization as follows

1. It counts the leading number of zeros in the fraction part starting from the hidden bit.

2. Decrements the exponent by the same number of bits.

3. Left shift the fraction by the same number of bits

4. Makes the hidden bit finally ' 1 '

5. Takes the rounding mode decision depending on mode_in_fpu input to the main entity and performs rounding off of the fraction part.

6. The fraction part is truncated.

7. Sends the outputs to the exception unit.

8. Checks if any data has been lost during rounding.

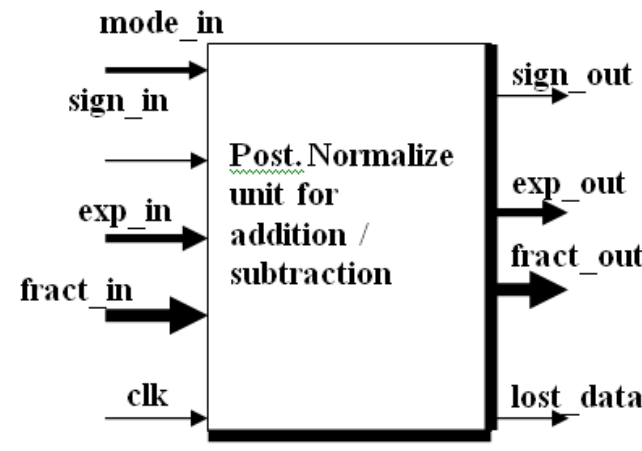

Fig. 8: Post Normalization Unit

Table 4: Inputs / Outputs Post-Normalization Unit

\begin{tabular}{|c|c|c|}
\hline Input & $\begin{array}{l}\text { No. of } \\
\text { bits }\end{array}$ & Description \\
\hline $\mathrm{Clk}$ & & Clock input to this block \\
\hline sign_in & 1 & $\begin{array}{l}\text { Resulting sign bit from the } \\
\text { addition subtraction unit }\end{array}$ \\
\hline exp_in & 8 & $\begin{array}{l}\text { Resulting exponent from pre- } \\
\text { normalize unit }\end{array}$ \\
\hline fract_in & 28 & $\begin{array}{l}\text { Resulting fraction after } \\
\text { computation from addition / } \\
\text { subtraction }\end{array}$ \\
\hline mode_in & 2 & $\begin{array}{l}\text { Mode_in_fpu input given to } \\
\text { it to take rounding decesions }\end{array}$ \\
\hline fract_out & 23 & Normalized fraction result \\
\hline exp_out & 9 & $\begin{array}{l}\text { Exponent output ( } 9 \text { th bit is } \\
\text { carry to check if the result is } \\
\text { overflowing after } \\
\text { incrementing }\end{array}$ \\
\hline sign_out & 1 & Sign bit of the result \\
\hline lost_data & 1 & $\begin{array}{l}\text { Tells if any data has been } \\
\text { lost during normalization }\end{array}$ \\
\hline
\end{tabular}

\section{Pre-Normalize unit for multiplication:}

The input operands to the FPU main entity are fed to the pre-normalization unit shown in Fig. 9 and are described in Table 5. It performs the following functions:-

1. Takes 32-bit input operands and separates the sign bit, exponent and fraction part as per IEEE754 standard.

2. It recovers the hidden bit.

3. Changes the length of the exponents and adds them.

4. Subtract the bias of 127 from the exponent so that only 127 is the bias added to the result but not 254

5. Calculates the sign bit and sends the results to the multiplication unit. 


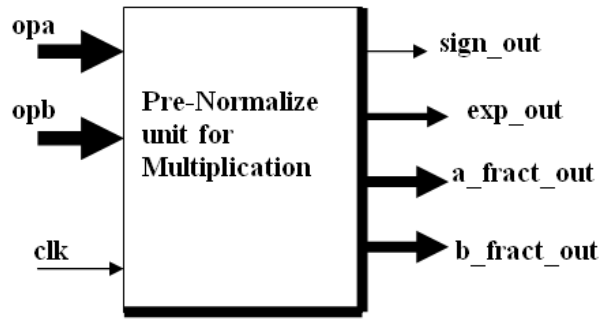

Fig. 9: Pre-Normalize unit for multiplication

Table 5: Pre-Normalize unit for multiplication

\begin{tabular}{|c|c|c|}
\hline $\begin{array}{l}\text { Input / } \\
\text { Output }\end{array}$ & $\begin{array}{l}\text { No. of } \\
\text { bits }\end{array}$ & Description \\
\hline clk3 & & $\begin{array}{l}\text { Clock signal for } \\
\text { this block }\end{array}$ \\
\hline Opa & 32 & $\begin{array}{l}\text { Input operand A of } \\
\text { the main entity }\end{array}$ \\
\hline Opb & 32 & $\begin{array}{l}\text { Input operand B of } \\
\text { the main entity }\end{array}$ \\
\hline a_fract_out & 24 & $\begin{array}{l}\text { Fraction A (with } \\
\text { hidden bit) }\end{array}$ \\
\hline b_fract_out & 24 & $\begin{array}{l}\text { Fraction B (with } \\
\text { hidden bit) }\end{array}$ \\
\hline exp_out & 10 & $\begin{array}{l}\text { Output exponent } \\
\text { after adding them }\end{array}$ \\
\hline sign_out & 1 & $\begin{array}{l}\text { Resulting sign of } \\
\text { two inputs }\end{array}$ \\
\hline
\end{tabular}

\section{Multiplication Unit}

It takes the fraction part from pre-normalize unit for multiplication unit as the output and gives the product as the output as shown in Fig. 10 and is described in Table 6.

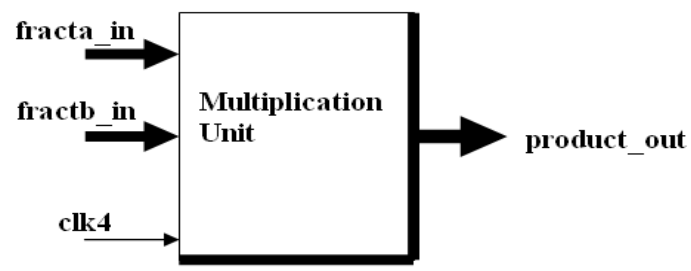

Fig. 10: Multiplication Unit

Table 6: Inputs / Outputs for Multiplication

\begin{tabular}{|l|c|l|}
\hline Input / output & $\begin{array}{l}\text { No. of } \\
\text { bits }\end{array}$ & Description \\
\hline clk4 & 24 & $\begin{array}{l}\text { Act as clock for this } \\
\text { block }\end{array}$ \\
\hline fracta_in & $\begin{array}{l}\text { Fraction of operand } \\
\text { A i.e. output of pre- } \\
\text { normalize unit }\end{array}$ \\
\hline fractb_in & 24 & $\begin{array}{l}\text { Fraction of operand } \\
\text { A i.e. output of pre- } \\
\text { normalize unit }\end{array}$ \\
\hline product_out & 49 & $\begin{array}{l}\text { Product output of two } \\
\text { fraction inputs }\end{array}$ \\
\hline
\end{tabular}

\section{Post-normalization unit for multiplication}

It is shown in Fig. 11 and is described in Table 7. It performs the following functions:-

1. Count the number of zeros starting from the left.

2. Decrements the value of exponent accordingly

3. Shifting the fraction part to the left by the number of zeros.

4. Rounding the result depending on the mode_in_fpu signal of the FPU unit.

5. Truncates the fraction part

6. Also, checks if there is any loss of data.

7. Sends the sign bit, exponent and fraction part and information about the loss of data to the exception unit.

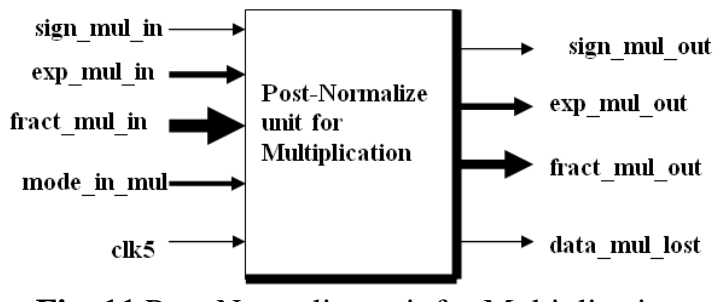

Fig. 11 Post-Normalize unit for Multiplication

Table 7: Inputs / Outputs for post-normalization of multiplication

\begin{tabular}{|l|c|l|}
\hline $\begin{array}{l}\text { Input / } \\
\text { Output }\end{array}$ & $\begin{array}{l}\text { No. of } \\
\text { bits }\end{array}$ & Description \\
\hline clk5 & & $\begin{array}{l}\text { Act as clock to this } \\
\text { unit }\end{array}$ \\
\hline sign_mul_in & 1 & $\begin{array}{l}\text { Output from the pre- } \\
\text { normalization unit } \\
\text { denoting the sign of } \\
\text { the result }\end{array}$ \\
\hline exp_mul_in & 10 & $\begin{array}{l}\text { Exponent output from } \\
\text { pre-normalize unit. }\end{array}$ \\
\hline fract_mul_in & 49 & $\begin{array}{l}\text { Product result of the } \\
\text { multiplication unit }\end{array}$ \\
\hline mode_in_mul & 2 & $\begin{array}{l}\text { Rounding mode } \\
\text { decisions are taken } \\
\text { depending on its value. }\end{array}$ \\
\hline sign_mul_out & 1 & Sign bit of the result \\
\hline exp_mul_out & 9 & $\begin{array}{l}\text { Exponent part of the } \\
\text { result }\end{array}$ \\
\hline fract_mul_out & 23 & $\begin{array}{l}\text { Fraction part of the } \\
\text { result }\end{array}$ \\
\hline data_mul_lost & 1 & $\begin{array}{l}\text { Data lost or not during } \\
\text { truncation of the } \\
\text { fraction part }\end{array}$ \\
\hline
\end{tabular}

\section{Exception Unit}

This unit shown in Fig 12 allows implementing the special values in the floating point unit and signals them whenever necessary i.e. invalid input or invalid operation. Foe example $\infty$ $+/-\infty$. The interface of the unit is described in Table 8. 
Table 8 Inputs / Outputs of Exception Unit

\begin{tabular}{|c|c|c|}
\hline Input / Output & $\begin{array}{l}\text { No. of } \\
\text { bits }\end{array}$ & Meaning \\
\hline clk_in_exc & & $\begin{array}{l}\text { Act as clock for this } \\
\text { unit }\end{array}$ \\
\hline opa_in_exc & 32 & $\begin{array}{l}\text { Operand A to check } \\
\text { exception foe input }\end{array}$ \\
\hline opb_in_exc & 32 & $\begin{array}{l}\text { Operand B to check } \\
\text { exception foe input }\end{array}$ \\
\hline sign_in_exc & 1 & Sign bit of the result \\
\hline exp_in_exc & 9 & Exponent of the result \\
\hline fract_exc & 23 & $\begin{array}{l}\text { Fraction part of the } \\
\text { result }\end{array}$ \\
\hline data_lost_exc & 1 & $\begin{array}{l}\text { Data lost (output from } \\
\text { post-normalization } \\
\text { unit }\end{array}$ \\
\hline fpu_op_exc & 2 & Opcode input to FPU \\
\hline output_exc & 32 & $\begin{array}{l}\text { Combined result after } \\
\text { computatin }\end{array}$ \\
\hline nan_in_exc & 1 & If the input is \\
\hline zero_exc & 1 & If an input is NaN \\
\hline in_exact_exc & 1 & $\begin{array}{l}\text { If there is a loss of } \\
\text { data }\end{array}$ \\
\hline overflow_exc & 1 & $\begin{array}{l}\text { If the result is } \\
\text { exceeding the } \\
\text { maximum limit }\end{array}$ \\
\hline op_nan_exc & 1 & $\begin{array}{l}\text { If an invalid operation } \\
\text { is performed }\end{array}$ \\
\hline
\end{tabular}

Inputs to FPU Two 32-bits operands in IEEE-754 floating point format along with the opcode, rounding mode select and clock are given as inputs to FPU. Table below shows the inputs and their functioning.

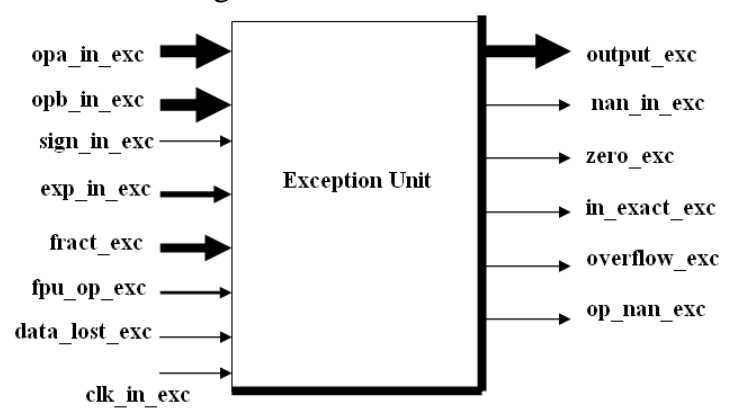

Fig. 12 Exception Unit

\section{FPU Unit}

Interface of top level entity is shown in Fig. 12 and are described in Table 9.1 and Table 9.2.

Table 9.1 Inputs of FPU

\begin{tabular}{|l|l|l|l|}
\hline Input & $\begin{array}{l}\text { No. } \\
\text { of } \\
\text { bits }\end{array}$ & $\begin{array}{l}\text { Descripti } \\
\text { on }\end{array}$ & Values \\
\hline clk_in_fpu & & $\begin{array}{l}\text { Give } \\
\text { clock } \\
\text { signal to }\end{array}$ & \\
\hline
\end{tabular}

\begin{tabular}{|c|c|c|c|}
\hline & & $\begin{array}{l}\text { FPU and } \\
\text { all its } \\
\text { internal } \\
\text { blocks }\end{array}$ & \\
\hline opa_in_fpu & 32 & $\begin{array}{l}\text { Operand } \\
\text { input } \mathrm{A} \text { to } \\
\text { the unit }\end{array}$ & \\
\hline opb_in_fpu & 32 & $\begin{array}{l}\text { Operand } \\
\text { input B to } \\
\text { the unit }\end{array}$ & \\
\hline mode_in_fpu & 2 & $\begin{array}{l}\text { Select } \\
\text { rounding } \\
\text { mode }\end{array}$ & $\begin{array}{l}\text { "00" - Round } \\
\text { up } \\
\text { "01" - Round } \\
\text { down } \\
\text { "10" - Round } \\
\text { to zero } \\
\text { "11" - Round } \\
\text { to even }\end{array}$ \\
\hline op_code & 2 & $\begin{array}{l}\text { Selects } \\
\text { the } \\
\text { operation }\end{array}$ & $\begin{array}{l}\text { "00"- } \\
\text { Addition } \\
\text { "01" - } \\
\text { Subtraction } \\
\text { "10"- } \\
\text { Multiplication } \\
\text { "11" - Left } \\
\text { for future use }\end{array}$ \\
\hline
\end{tabular}

Table 9.2 Output of FPU

\begin{tabular}{|l|c|l|}
\hline Outputs & $\begin{array}{l}\text { No. of } \\
\text { bits }\end{array}$ & Meaning \\
\hline Output & 32 & $\begin{array}{l}\text { Result of arithmetic } \\
\text { operation }\end{array}$ \\
\hline nan_in & 1 & $\begin{array}{l}\text { Either of the input is } \\
\text { NaN }\end{array}$ \\
\hline Overflow & 1 & $\begin{array}{l}\text { Result exceeding } \\
\text { maximum limit }\end{array}$ \\
\hline in_exact & 1 & $\begin{array}{l}\text { Loss of data while } \\
\text { rounding }\end{array}$ \\
\hline Zero & 1 & $\begin{array}{l}\text { Result is zero in } \\
\text { fraction part }\end{array}$ \\
\hline op_nan & 1 & $\begin{array}{l}\text { Invalid operation } \\
\text { performed }\end{array}$ \\
\hline
\end{tabular}

\section{SIMULATION RESULTS}

The design has been simulated and synthesized on Xilinx 13.1 ISE Design Suite. It has been synthesized on Vitex 5 FPGA module. Fig. 13.a, b, c, d shows the simulated waveform for the pre-normalized, addition / subtraction and postnormalized units, output of addition from FPU top module. 


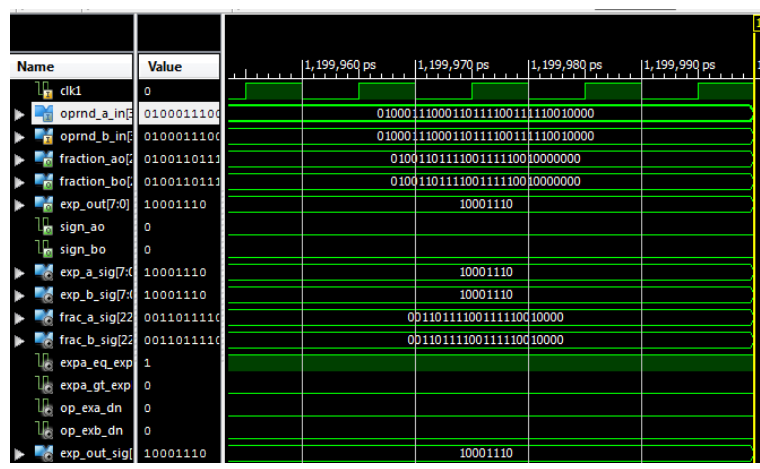

Fig. 13a. Pre-Normalize FPU for addition / subtraction

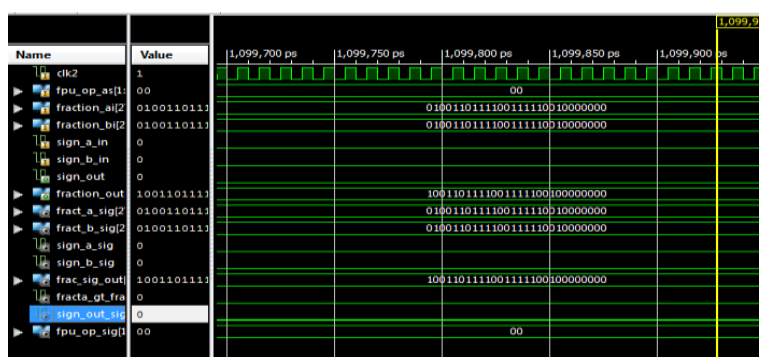

Fig. 13b: Addition / Subtraction Unit

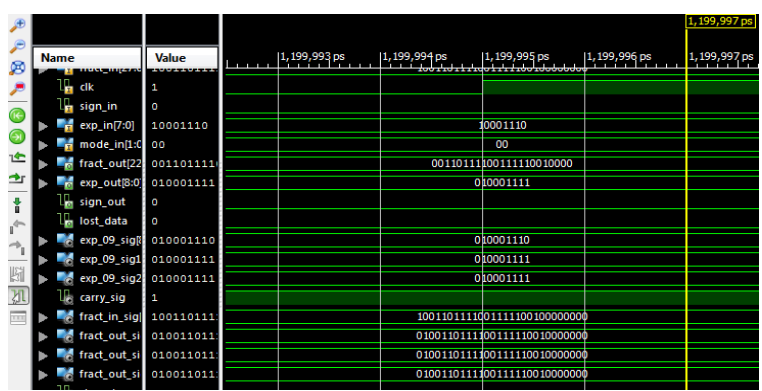

Fig. 13c Post-Normalize Unit for addition / Subtraction

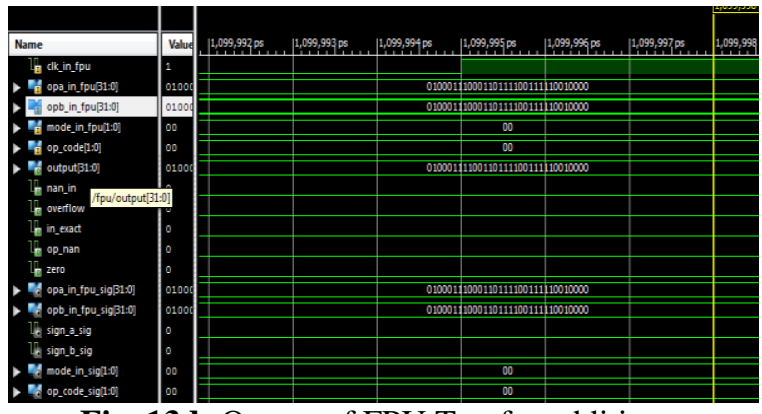

Fig. 13d: Output of FPU Top for addition

Similarly pre-normalize unit for multiplication, multiplication and post-normalize unit for multiplication have been implemented and final output of multiplication from FPU top have been simulated. Product output of two floating point numbers by FPU is shown in Fig. 14.

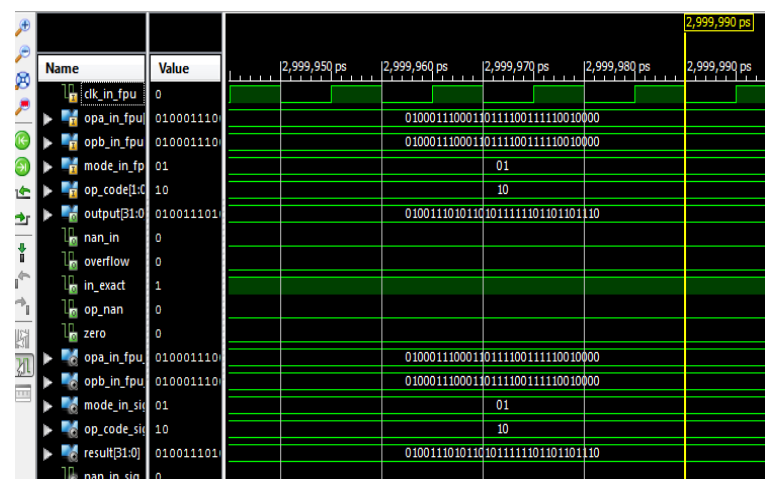

Fig. 14: Product output of Multiplier

Fig. 15a, b, c shows the schematic, synthesis report for device utilization summary and timing report respectively.

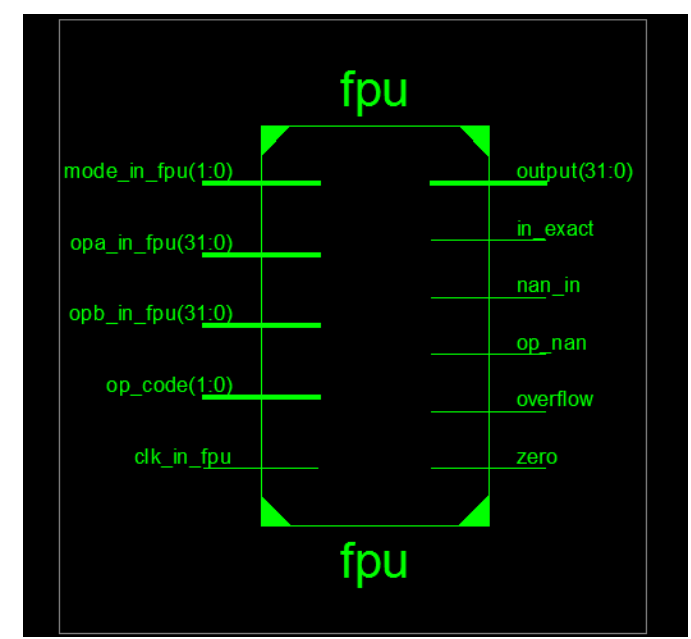

Fig.15a: Schematic of the FPU Unit

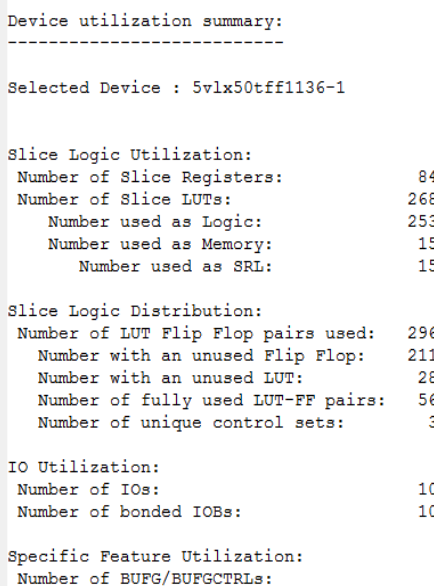

Fig.15b: Device Utilization Summary of FPU 


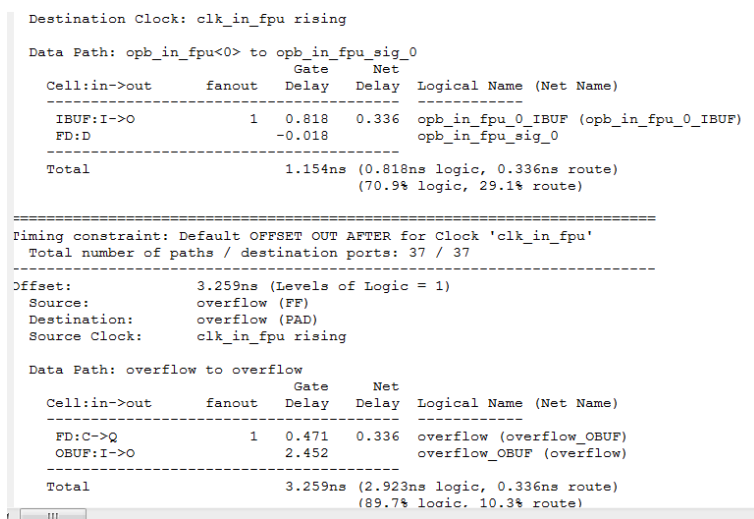

Fig. 15c: Timing Summary of FPU

Table 10 shows the hardware requirement of the design.

Table 10: Hardware Utilization Summary

\begin{tabular}{|l|l|l|}
\hline S.No. & Slice Logic & Utilization \\
\hline $\mathbf{1}$ & $\begin{array}{l}\text { Number of Slice } \\
\text { Registers }\end{array}$ & $\begin{array}{l}845 \text { out of } \\
28800 \quad 2 \%\end{array}$ \\
\hline $\mathbf{2}$ & $\begin{array}{l}\text { Number of Slice } \\
\text { LUTs }\end{array}$ & $\begin{array}{l}2683 \text { out of } \\
288009 \%\end{array}$ \\
\hline $\mathbf{3}$ & $\begin{array}{l}\text { Number used as } \\
\text { Logic }\end{array}$ & $\begin{array}{l}2532 \text { out of } \\
28800 \quad 8 \%\end{array}$ \\
\hline $\mathbf{4}$ & Number used as & $\mathbf{1 5 1}$ out of \\
& Memory & $\mathbf{1 6 8 0} 1 \%$ \\
\hline $\mathbf{6}$ & Number of IOs: & $\mathbf{1 0 6}$ \\
\hline $\mathbf{7}$ & Number of & $\mathbf{1}$ \\
& BUFG/BUFGCTRLs & \\
\hline
\end{tabular}

\section{CONCLUSION}

In this paper, floating point unit has been designed, simulated and then synthesized in order to obtain its performance in terms of the area occupied and delay on Vitex 5 FPGA Module. For the data path opb_in_fpu to opb_in_sig_0 total combinational logic delay and routing delay is $1.154 \mathrm{~ns}$ and total overflow to overflow delay is 3.259 ns. Hardware requirements have also been specified in the paper. Prenormalization and postnormalization units of the FPU can be further optimized to reduce the hardware requirement as well as delay.

\section{REFERENCES}

[1]. K. K. Lasith, Anoop Thomas "Efficient implementation of single precision floating point processor in FPGA", Proceedings Emerging Research Areas: Magnetics, Machines and Drives (AICERA/iCMMD), 2014 Annual International Conference on 4-26 July 2014, Kottayam, India

[2]. Seungchul Kim, Yongjoo Lee, Wookyeong Jeong "Low cost floating point arithmetic unit design", ASIC, 2002. Proceedings. 2002 IEEE Asia-Pacific Conference on 8-8 Aug. 2002, Taipei, Taiwan, Taiwan.

[3]. Naresh Grover, M. K. Soni, "Design of FPGA based 32-bit Floating Point Arithmetic Unit and verification of its VHDL code 9 using MATLAB", I. J. Information Engineering and Electronics Business, Jan. 2014, pp 1-14

[4]. A. Malik, "Seok-Bum Ko, Effective implementation of floating-point adder using pipelined LOP in FPGAs," Proceedings Electrical and Computer Engineering, 2005. Canadian Conference on, vol., no., pp. 706709, 1-4 May 2005.

[5]. Sayali A. Bawankar, Prof. G. D. Korde, "Review on 32 bit single precision Floating point unit (FPU) Based on IEEE 754 Standard using VHDL", International Research General of Engineering and Technology, Vol. 4, Issue 02, Feb. 2017, pp 1077-1082. 